\title{
A STUDY ON MECHANICAL PROPERTIES AND STRUCTURE OF ANHYDRITE BINDER MODIFIED BY ULTRA-DISPERSED SILTSTONE
}

\author{
Yury TOKAREV (1) ${ }^{*}$, Grigory YAKOVLEV ${ }^{1}$, Zarina SAIDOVA ${ }^{1}$, Valery GRAKHOV ${ }^{1}$, \\ Alexander BURYANOV ${ }^{2}$, Ali Elsaed Mohamed Mohamed ELREFAI ${ }^{3}$ \\ ${ }^{1}$ Department of Building Materials, Mechanization and Geotechnics, Kalashnikov Izhevsk State Technical \\ University, Studencheskaya Str. 7, 426069 Izhevsk, Russian Federation \\ ${ }^{2}$ Faculty of Civil Engineering, Moscow State University of Civil Engineering, Yaroslavskoye Shosse 26, \\ 129337 Moscow, Russian Federation \\ ${ }^{3}$ Egyptian Russian University, 87 El-Tahrir St., Cairo, Egypt
}

Received 24 November 2019; accepted 28 December 2019

\begin{abstract}
This research is devoted to modification of physical and mechanical properties and structure of a binder based on natural anhydrite. A sedimentary rock siltstone was added into the composition as a mineral ultrafine additive. The presence of aluminosilicate minerals proves that finely ground siltstone can be used as a mineral additive in the composition of the anhydrite binder, accelerating crystallization of gypsum new formations and densifying the structure of gypsum stone. For the first time, the effectiveness of using sodium and ammonium phosphates as hardening activators of an anhydrite binder was shown. Siltstone, added to the composition in the amount from 0 to $5 \%$, lead to up to $40 \%$ increase in strength, which is due to the action of siltstone particles as "crystallization centers" and formation of crystalline hydrates of calcium sulfate dihydrate on their surface. Combined action of calcined siltstone and lime leads to a $45 \%$ increase in strength due to the additional compaction by new hydration products formed in the course of metakaolin and lime interaction. Microstructural analysis showed that samples with calcined siltstone and lime have a more dense and uniform structure with a lower porosity, compared to those with only natural siltstone.
\end{abstract}

Keywords: anhydrite, mechanical tests, differential scanning calorimetry, IR spectral analysis, microstructure.

\section{Introduction}

Nowadays resource-efficient and energy-saving technologies are becoming key fields of building materials science, making it necessary to use new types of natural raw materials, such as natural anhydrite, as a sort of gypsum. It is known that anhydrite deposits lay under gypsum layers, so the production of natural anhydrite binders is recommended to be organized at the existing gypsum quarries and factories. Anhydrite binders can be obtained by high-temperature firing of gypsum stone as well as by fine grinding of anhydrite stone with the addition of hardening activators. At the same time, the properties of anhydrite, both artificial and natural, are significantly different from that of gypsum binder (Sergeeva \& Sycheva, 2017; Wang et al., 2013) due to greater reactivity and surface activity.

The literature review showed that anhydrite can be used both as an aggregate in composite materials (Magallanes-Rivera \& Escalante-García, 2014) and as a cement hardening retarder (Tzouvalas et al., 2004). In our country, the production of natural anhydrite binders is currently at a very low scale, due to the fact that raw materials of each particular deposit are not studied well enough and their physical and mechanical characteristics are not sufficient to create composite materials for various application fields.

It is known that anhydrite should be used together with hardening activators. P. P. Budnikov stated that natural anhydrite can be activated through various additives - acids, alkalis, salts, lime, blast furnace slags. As hardening activators, both alkaline and sulfate additives can be used (Sergeeva \& Sycheva, 2017; Singh \& Garg, 2000, 2004). The authors of Altykis et al. (1996) note that the mechanism of dissolution and crystallization of new formations from a supersaturated solution is dominant in the hydration of insoluble anhydrite, so it is recommended to use mainly alkaline additives - potassium and

${ }^{*}$ Corresponding author. E-mail: tokarev_01@list.ru 
sodium sulfates, Portland cement, caustic dolomite, air lime, etc. Along with the dissolution of anhydrite binder, it is important to create conditions for crystallization of gypsum neoplasms, which can be achieved using mineral additives and plasticizers. The combined effect of activators and mineral additives (Magallanes-Rivera et al., 2012; Sakthieswaran \& Sophia, 2018, 2019) leads to the significant increase in physical and mechanical characteristics of the final composition. The authors of Fomina et al. (2018) showed that argillite can be used effectively as an aggregate in the production of aerated concrete. It is known (Chen et al., 1993; Juenger et al., 2019), that aluminosilicate rocks are widely used as a partial replacement of cement in the production of concrete in order to reduce the production energy-output ratio. They can also be used as pozzolanic additives. However, there is no information in the literature on phosphate activators to be previously used to accelerate anhydrite binders hardening process, as well as siltstone (aluminosilicate rocks of sedimentary origin) is not described to be used as a mineral additive.

The aim of this research was to study physical and mechanical properties and structure of a binder, based on natural anhydrite of the Ergachinsky deposit, with phosphate activators used as cement hardeners, and siltstone used as an active ultrafine additive. At the first stages, the following tasks were set:

1 . To justify the choice and study the properties of sedimentary rock - siltstone;

2. To study the effect of phosphate activators on the mechanical properties of anhydrite binder;

3. To determine mechanical properties of anhydrite binder modified with a complex of additives;

4. To optimize the additives content in the anhydrite binder composition;

5. To study the structure of anhydrite binder.

\section{Materials and methods}

Samples were prepared with anhydrite of the Ergachinsky deposit from Kungursky district of Perm region. Anhydrite was first crushed in the SchD-6 jaw crusher and then ground in an ID-200 disk mill to the specific surface of $0.3 \mathrm{~m}^{2} / \mathrm{g}$. Particle size analysis showed that about $60 \%$ of the particles were in the range from 0.04 to 0.5 microns. Nevertheless, the composition of the particles contained large particles with a size of 10 to 100 microns, which impaired physical and mechanical characteristics of the gypsum stone. To increase the solubility of the anhydrite binder, phosphate-based hardening activators were introduced to the composition. A sedimentary rock, siltstone, was used as a mineral ultrafine additive. Siltstone was introduced both in natural (unburned) and calcined form. In both cases, it was crushed and ground to a disperse state. The particle size analysis of the additive, carried out on a laser dispersion analyzer, showed that the average particle size is 34.5 microns. Heat treatment of siltstone was carried out at the temperature range of $600-650{ }^{\circ} \mathrm{C}$ in a muffle furnace for 5-7 hours. In order to reveal the pozzolanic properties of the calcined siltstone, lime in the amount of $3 \%$ was introduced into the composition of the anhydrite binder.

Prismatic specimens with dimensions $4 \times 4 \times 16 \mathrm{~cm}$ were prepared, kept in the molds for 24 hours at $\mathrm{T}=20$ ${ }^{\circ} \mathrm{C}$ under normal humidity with further mechanical durability tests at the age of 7 days. The strength tests of the samples have been carried out on hydraulic press PGM100 with the allowed load $100 \mathrm{kN}$ and loading speed 0.5 $\mathrm{MPa} / \mathrm{s}$. The average values calculated by the results of three successful measurements have been taken as the final test results. The ground siltstone has been mixed with tempering water and hardening activator and introduced into the anhydrite binder. The optimal quantity of water has been taken from the binder mass to obtain the anhydrite dough with normal density. The components have been mixed manually within $2-2.5$ minutes.

The X-ray phase analysis has been carried out on diffractometer DRON-2. Cobalt has been applied as an anticathode. Differential scanning calorimetry (DSC) of the samples was carried out with the help of derivatograph TGA/DSC-1 "Mettler Toledo". Differential-thermal analysis has been carried out at the temperature range from 0 up to $1050{ }^{\circ} \mathrm{C}$ with heating rate $10{ }^{\circ} \mathrm{C} / \mathrm{min}$. IR spectral analysis was carried out with the help of Shimadzu IR Fourier spectrometer IRAffinity-1. For analysis, tablets were prepared by thoroughly mixing a finely ground sample with powder $\mathrm{KBr}$, then the mixture was pressed into a mold. For dispersion analysis, a laser dispersion analyzer SALD-7500nano was used.

Chemical and mineralogical composition has a major influence on the reactivity of mineral additives. An X-ray phase analysis, used to study the composition of siltstone (Figure 1), showed the most intense reflection lines on the spectrum, corresponding to crystalline silicon oxide $\mathrm{SiO}_{2}$ $\left(\mathrm{d}_{\alpha}=4,26 \AA ; 2,46 \AA ; 2,28 \AA ; 2,13 \AA\right.$; $1,98 \AA$; $1,82 \AA$; $1,67 \AA$; $1,54 \AA$; $1,45 \AA ; 1,38 \AA$ ), calcite $\mathrm{CaCO}_{3}\left(\mathrm{~d}_{\alpha}=3,03 \AA\right.$ ) $)$, kaolinite $\mathrm{Al}_{2} \mathrm{O}_{3} \cdot 2 \mathrm{SiO}_{2} \cdot 2 \mathrm{H}_{2} \mathrm{O}\left(\mathrm{d}_{\alpha}=7,16 \AA\right.$; $4,50 \AA ; 3,34 \AA$;

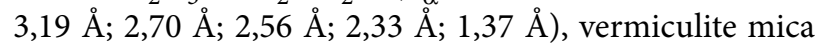
$\left(\mathrm{d}_{\alpha}=14,35 \AA ; ; 6,36 \AA ; 3,49 \AA\right)$.

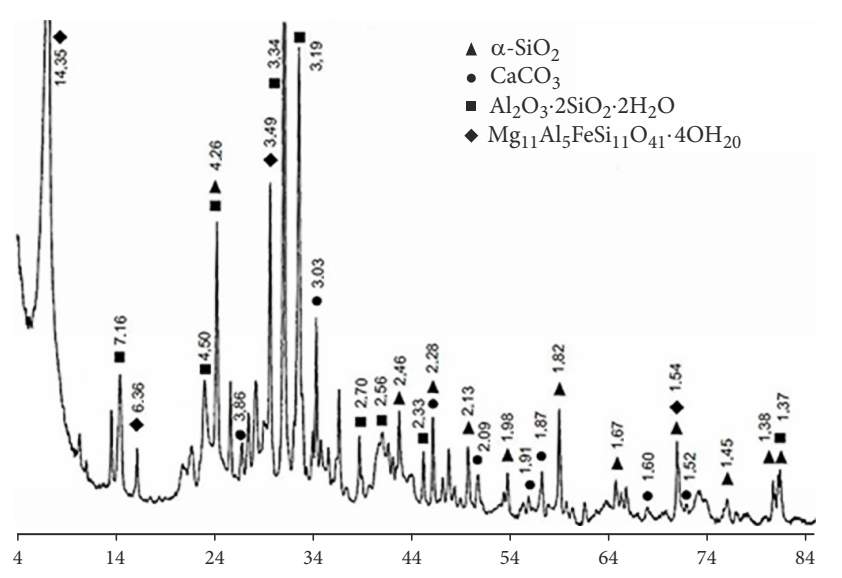

Figure 1. X-ray diffraction pattern of siltstone 


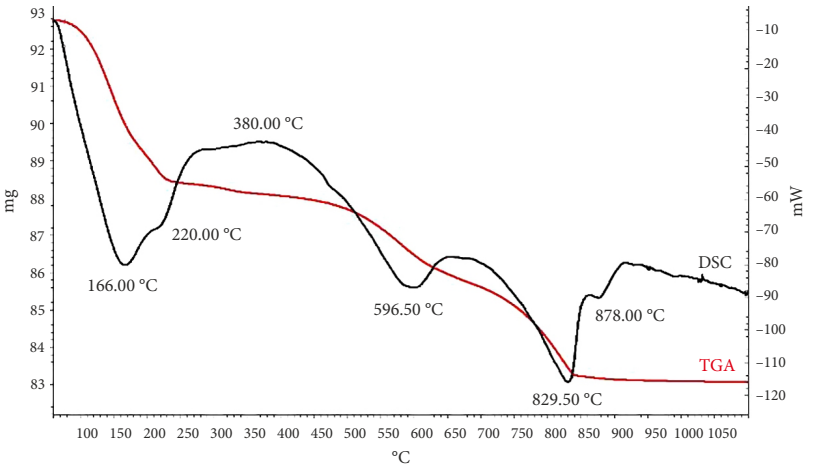

Figure 2. Derivatogram of siltstone

Differential scanning calorimetry (DSC) and infrared spectral analysis (IR) were used to detect changes in the structure of the samples. Differential-thermal analysis (Figure 2) of siltstone confirmed the presence of crystalline hydrated water in the additive (endothermal effects at temperatures of 166 and $220^{\circ} \mathrm{C}$ ). Exothermal effect at the temperature of $380^{\circ} \mathrm{C}$ shows that there is an organic com- ponent in the composition of siltstone. The endothermal effect at the temperature of $596.5^{\circ} \mathrm{C}$ is associated with the formation of metakaolinite during the destruction of the kaolinite crystal lattice. At the temperature of $829.5^{\circ} \mathrm{C}$, the endothermic effect with the simultaneous loss of water, noted on the thermogravimetric curve, is associated with the loss of constitutional water from vermiculite and decomposition of calcium carbonate. At temperatures of 900-950 ${ }^{\circ} \mathrm{C}$, mullite is formed due to recrystallization of amorphous silica and alumina.

Microstructural analysis of siltstone (Figure 3a) showed the presence of quartz sand, feldspar, and mica particles (Figure $3 \mathrm{~b}$ ), bonded by clay inclusions. In the field analysis, calcium carbonate was detected (reaction to a solution of hydrochloric acid with the release of carbon dioxide).

An X-ray microanalysis (Figure 4) of lamellar formations on a cleaved sample of siltstone showed the presence of silicon $\mathrm{Si}$, aluminum $\mathrm{Al}$ and oxygen $\mathrm{O}$ atoms, which means that there are clay inclusions in the siltstone.
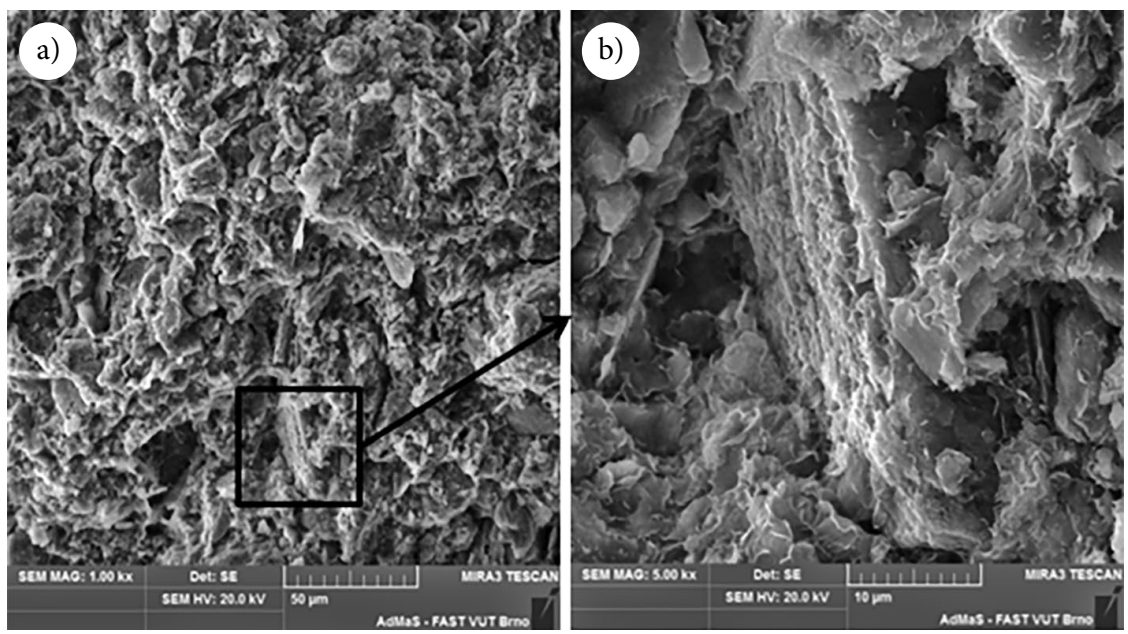

Figure 3. Microstructure of siltstone: a - general view of siltstone at a 1000-fold magnification; $\mathrm{b}$ - fragment of the microstructure with mica inclusions at a 5000-fold magnification

a)

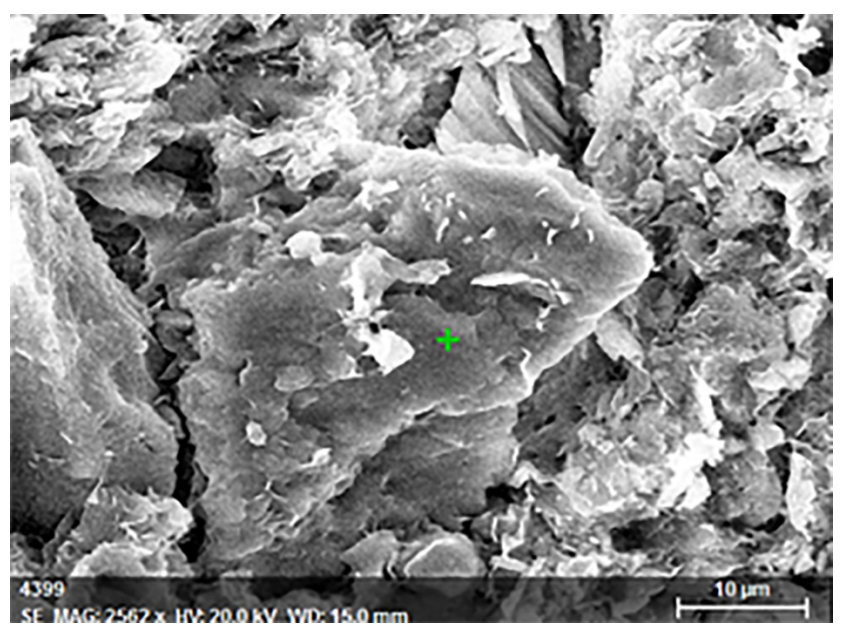

b)

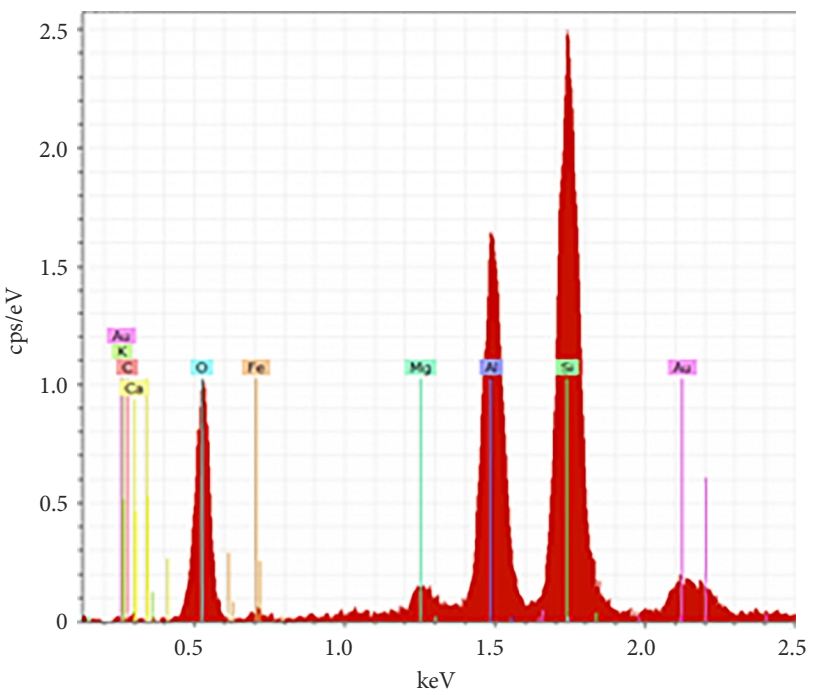

Figure 4. X-ray microanalysis of siltstone: a - clay inclusions; b - chemical composition of the siltstone microstructure fragment 
Thus, the chemical and mineralogical composition analysis, as well as microstructural analysis showed the presence of aluminosilicate minerals in siltstone with inclusions of mica, quartz, calcite and clay particles. Based on this, it is suggested to use finely ground siltstone as a mineral additive in the composition of the anhydrite binder in order to accelerate the crystallization of gypsum neoplasms and densify the structure of gypsum stone.

\section{Results and discussion}

\subsection{Mechanical tests}

It is known that hardening activators give anhydrite binder the ability to interact with water. At the same time, activators do not only affect the hydration of anhydrite, but also accelerate its structural formation (Kondratieva et al., 2017). However, the effectiveness of the additives may be different. In this research, the effect of hardening activators based on sodium and ammonium phosphates on the mechanical characteristics of an anhydrite binder was studied. For this, prismatic specimens with dimensions $4 \times 4 \times 16 \mathrm{~cm}$ were prepared and then tested at the age of 7 days.

Mechanical tests were carried out on samples modified with sodium phosphate in the amount of up to $10 \%$ (Figure 5a). The analysis of test results showed that in the range from 0 to $5 \%$, the compressive strength of the samples decreases. However, at the optimum additive content of 7\%, the strength of modified samples significantly increases and reaches 4 times or more than that of the reference sample. After passing this optimal value, the strength characteristics decrease again. When using ammonium hydrogen phosphate (Figure 5b), an increase in the strength of the sample reaches 2.5 times, which is less than with sodium phosphate. Conley and Bundi (1958) explained that the additives effect on the hydration process of anhydrite was associated with the formation of double salts, and the effectiveness of the additives depended on the presence of certain anions and cations

a)

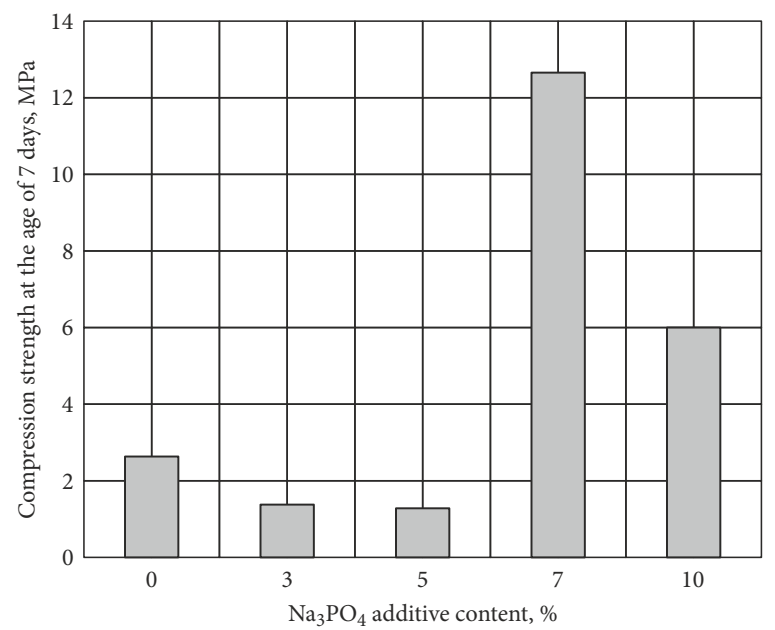

in its composition. It was noted in Singh and Middendorf (2007), that salts of various acids can both increase and decrease the mechanical characteristics of a gypsum binder, while additives significantly alter the morphology and microstructure of gypsum stone (Escalante-García et al., 2017). The authors of Altykis et al. (1996) state that mineral additives act as crystallization centers, and it is recommended to initiate the process of anhydrite dissolution using alkaline chemical additives. Supposedly, additives based on sodium and ammonium phosphates create a highly alkaline environment, which increases the degree of solubility of anhydrite and improves the course of hydration. However, high concentrations of sodium phosphate can cause significant efflorescence on the surface of anhydrite binder samples, and therefore additional measures should be taken to prevent this problem. This is why ammonium hydrogen phosphate in an amount of 3\% was used in further research as a hardening activator.

At the next stage, the effect of siltstone on the mechanical characteristics of the anhydrite binder was studied. The authors of Habert et al. (2009), Krejsová et al. (2018) noted that, depending on the chemical composition and origin of the aluminosilicate rock, natural aluminosilicate additives can affect the properties of cements and concrete in different ways. The analysis of mechanical testing results of samples at the age of 7 days with an additive content of 0 to $10 \%$ showed (Figure 6) that at an optimal additive content of $5 \%$ there is an increase in compressive strength of up to $40 \%$ compared to the reference sample. Further increase in the siltstone content, leads to a gradual decrease in strength. The results can be explained by the fact that the particles of ground siltstone act as "crystallization centers", on the surface of which crystalline calcium sulfate dehydrate are formed.

The presence of clay particles in the siltstone makes it possible to increase their activity by heat treatment with the formation of an active amorphous phase (metakaolinite), which can additionally densify the structure of the anhydrite matrix. Metakaolin is a product of monomineral

b)

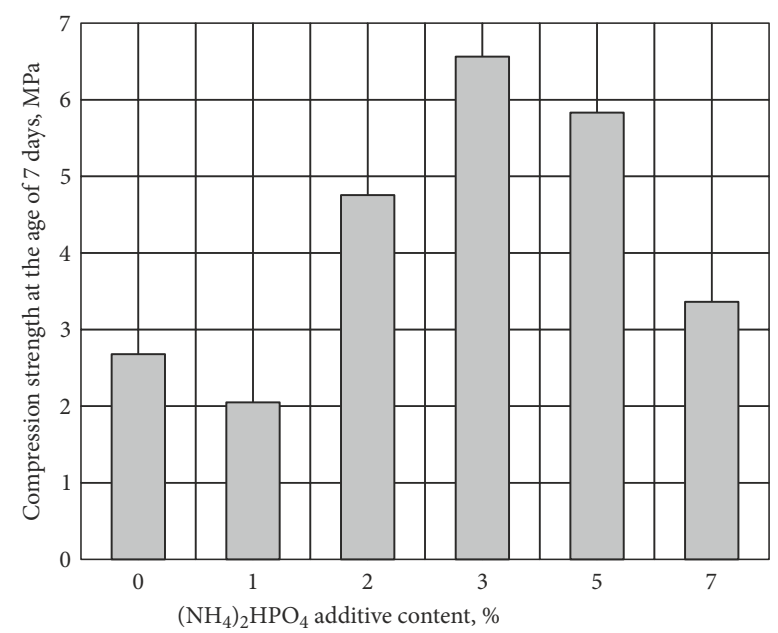

Figure 5. The dependence of the anhydrite binder strength on the phosphate activators content: a - with sodium phosphate; $\mathrm{b}$ - with ammonium phosphate 


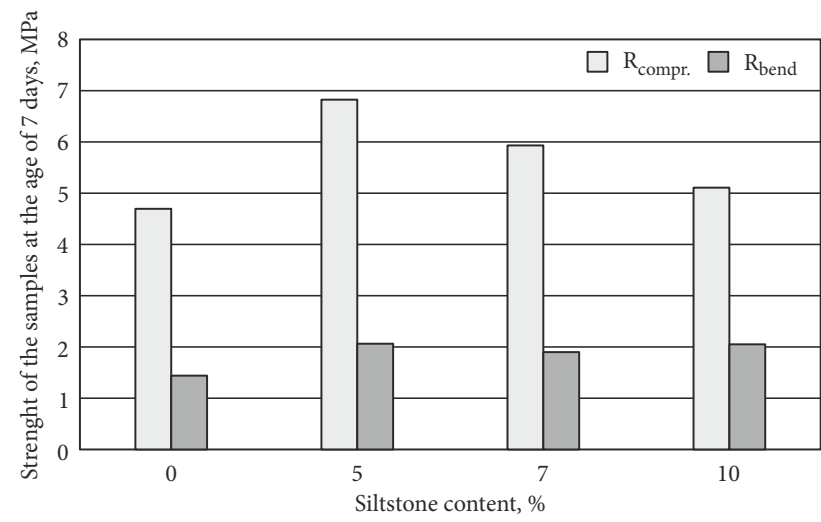

Figure 6. The dependence of the strength of anhydrite binder on the siltstone content

kaolinite clays $\left(\mathrm{Al}_{2} \mathrm{O}_{3} \cdot 2 \mathrm{SiO}_{2} \cdot 2 \mathrm{H}_{2} \mathrm{O}\right)$ heat treatment in the range of $650-800^{\circ} \mathrm{C}$. It is known that thermal treatment of gray argillite at a temperature of $600{ }^{\circ} \mathrm{C}$ increases the hydraulic activity of mixed cement (Konovalov et al., 2015). Thus, the decision was to burn additives in the temperature range $600-650^{\circ} \mathrm{C}$. Natural siltstone was fired in the PM-8 muffle furnace for 5-7 hours. IR analysis of the calcined siltstone showed a significantly reduced intensity of the absorption lines in the frequency range $1000-1050 \mathrm{~cm}^{-1}$ and $400-500 \mathrm{~cm}^{-1}$, corresponding to $\mathrm{Si}-\mathrm{O}$ and $\mathrm{Al}-\mathrm{O}$ bonds, which indicates a decrease in kaolinite content after heat treatment of the siltstone. Besides, significant frequency shifts are observed in these intervals, which indicates the formation of new phases in the siltstone.

In order to reveal the pozzolanic properties of metakaolin, lime in the amount of $3 \%$ was introduced into the composition of the anhydrite binder. Calcined siltstone was added into the composition of the anhydrite binder in an amount of 0 to $10 \%$ of the binder weight. Results of mechanical tests showed that the addition of calcined siltstone in the temperature range of $600-650{ }^{\circ} \mathrm{C}$ in the amount from 0 to $10 \%$ leads to a sharp decrease in the strength of anhydrite samples, reaching 4 times with the additive content of $10 \%$. Thus, heat treatment in the temperature range $600-650{ }^{\circ} \mathrm{C}$ leads to the distruction of the initial crystalline structure of kaolinite and formation of an amorphous phase (metakaolinite), which does not contribute to an increase in the activity of siltstone, but on the contrary, decreases it.

Mechanical tests results (Figure 7) showed a significant increase in compressive strength up to $45 \%$ with an optimum additive content of $7 \%$, compared to the sample without lime, where a drop in mechanical characteristics was observed. This can be the result of an interaction of metakaolin and lime, with the following gain in strength due to the formation of new hydration products.

\subsection{Differential scanning calorimetry}

Differential scanning calorimetry methods were used in order to explain previously obtained results and detect changes in the structure of the samples. The analysis of

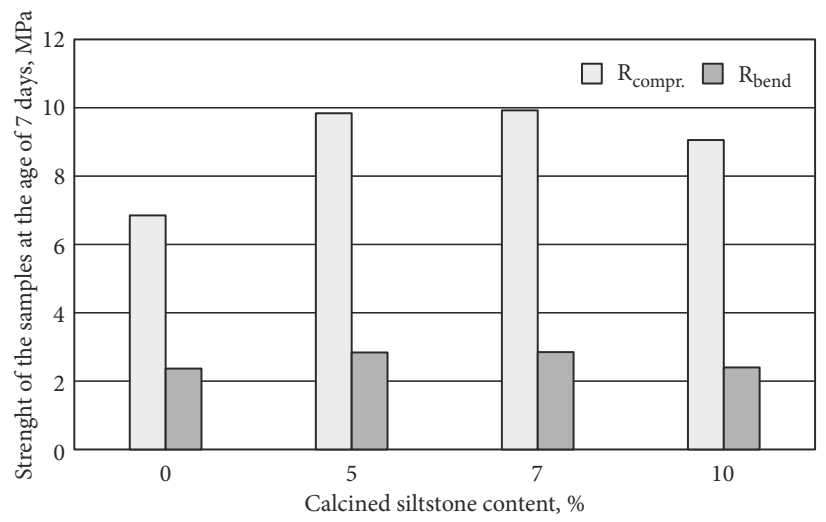

Figure 7. The dependence of the anhydrite binder strength on the content of siltstone, calcined in the temperature range $600-650{ }^{\circ} \mathrm{C}$, with the addition of lime

the spectra of the modified and reference samples (Figure 8) showed the presence of endothermal effects associated with the removal of crystalline hydrated water and exothermal effect, correlated with the rearrangement of the crystal lattice of calcium sulfate. Endothermal effects associated with the decomposition of calcium carbonate and partial dissociation of calcium sulfate were also noted. New peaks did not appear in the spectra, though there are differences in the values of temperature effects.

The spectrum of the sample with calcined siltstone (Figure 9) shows two new endothermic effects at temperatures of 479.50 and $780{ }^{\circ} \mathrm{C}$, associated with the formation of metakaolinite during the destruction of the kaolinite crystal lattice and following metakaolin decomposition.

Besides, the shape of the endothermic effect changes in the temperature range $150-200{ }^{\circ} \mathrm{C}$ - a peak with the maximum effect appears at a temperature of $184^{\circ} \mathrm{C}$, which might indicate the presence of other crystalline hydrates.

\subsection{IR spectral analysis}

The IR spectral analysis of the samples revealed (Figure 10) a considerable difference in the structure of the samples. For example, in the spectra of the samples without additives and with the addition of siltstone, strong frequency shifts corresponding to $\mathrm{SO}_{4}{ }^{2-}$ ions (1141.86 and $1138.00 \mathrm{~cm}^{-1}, 1118.71$ and $1116.78 \mathrm{~cm}^{-1}$ ) are observed, which indicate a change in crystalline hydrates structure. In addition, the frequencies of stretching vibration lines (3547.09 and $3552.88 \mathrm{~cm}^{-1}, 3408.22$ and $3406.29 \mathrm{~cm}^{-1}$ ) and deformation vibrations lines corresponding to water $\left(1622.13\right.$ and $1618.28 \mathrm{~cm}^{-1}$ ) change significantly. Given that new hydration products do not form with the addition of siltstone, it can mean that the additive is directly involved in the formation of the structure of gypsum stone.

When calcined siltstone is added, the spectrum also shows strong frequency shifts of $\mathrm{SO}_{4}{ }^{2-}$ ions (1141.86 and $1138.00 \mathrm{~cm}^{-1}, 594.08$ and $\left.596.00 \mathrm{~cm}^{-1}\right)$ and $\mathrm{H}_{2} \mathrm{O}$ stretching vibration ions $\left(3547.09\right.$ and $3545.16 \mathrm{~cm}^{-1}, 3408.22$ and $\left.3406.29 \mathrm{~cm}^{-1}\right)$. 
a)

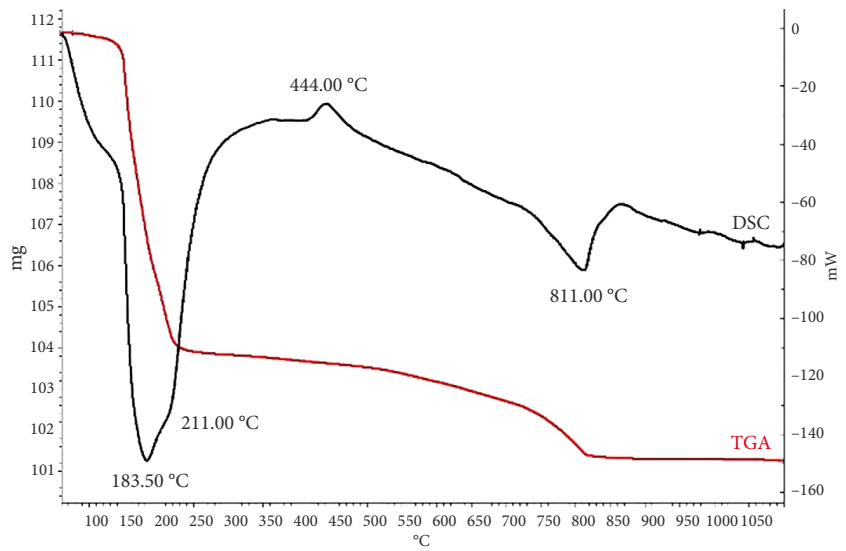

b)

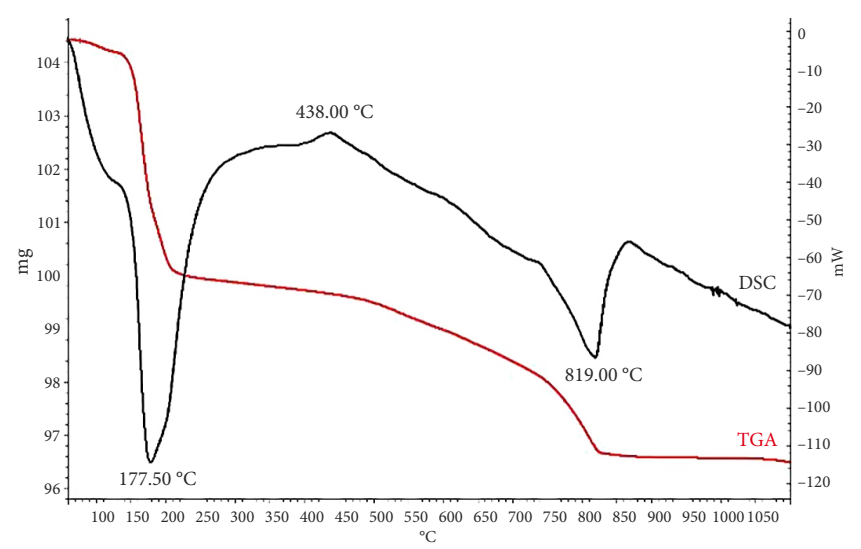

Figure 8. Derivatogram of an anhydrite binder: $\mathrm{a}$ - without siltstone; $\mathrm{b}$ - with the addition of natural siltstone

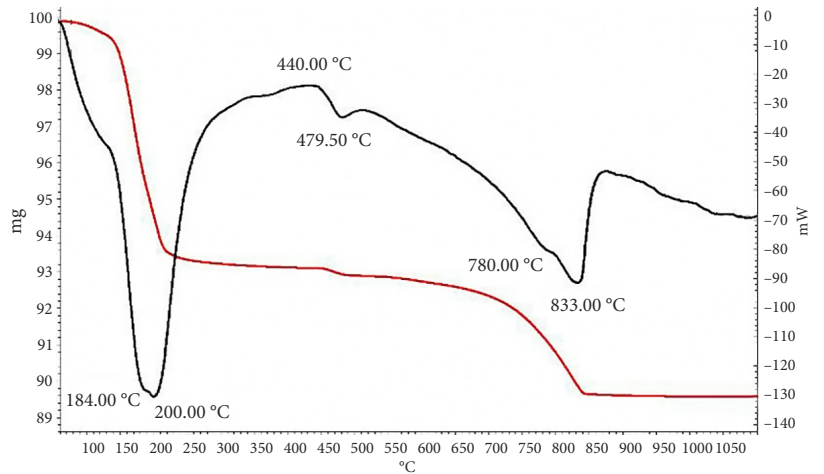

Figure 9. Derivatogram of an anhydrite binder: with the addition of calcined siltstone

\subsection{Microstructural analysis}

Microstructural analysis of the sample with the addition of natural siltstone (11a) showed an inhomogeneous structure due to the presence of crystalline hydrates of various shapes and sizes. When the calcined siltstone and lime are added into the composition together, an amorphous mass is formed on the surface of the sample (11b), which contributes to additional compaction and the formation of a

a)

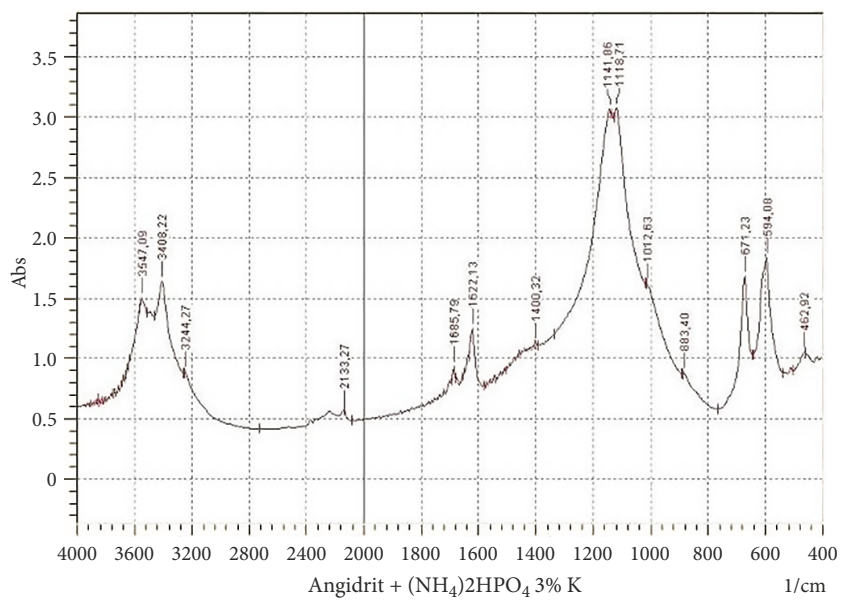

denser structure with less water permeability. An intergrowths of elongated crystals, which are distinguished by uniformity and high density, can also be noted on the Figure $11 \mathrm{~b}$ (in the lower right corner). Thus, the microstructure of the sample with the addition of calcined siltstone and lime is characterized by a denser and more uniform structure with an amorphous mass on the surface of the crystals, compared to the microstructure of the sample with the addition of natural siltstone.

An X-ray microanalysis of the sample with the addition of natural siltstone showed the presence of a significant number of calcium $\mathrm{Ca}$, sulfur $\mathrm{S}$ and oxygen $\mathrm{O}$ atoms, which indicates a high content of calcium sulfate dihydrate crystallohydrates in the composition of the gypsum stone. There are also, but in a smaller amount, silicon $\mathrm{Si}$, magnesium $\mathrm{Mg}$, aluminum $\mathrm{Al}$ and phosphorus $\mathrm{P}$ atoms, the presence of which is caused by an ultrafine additive siltstone and hardening activator - sodium hydrogen phosphate.

An X-ray microanalysis of the sample with the addition of calcined siltstone together with lime showed the presence of the same atoms, but in different ratios (Figure 12). Comparative analysis of sample spectra, presented

b)

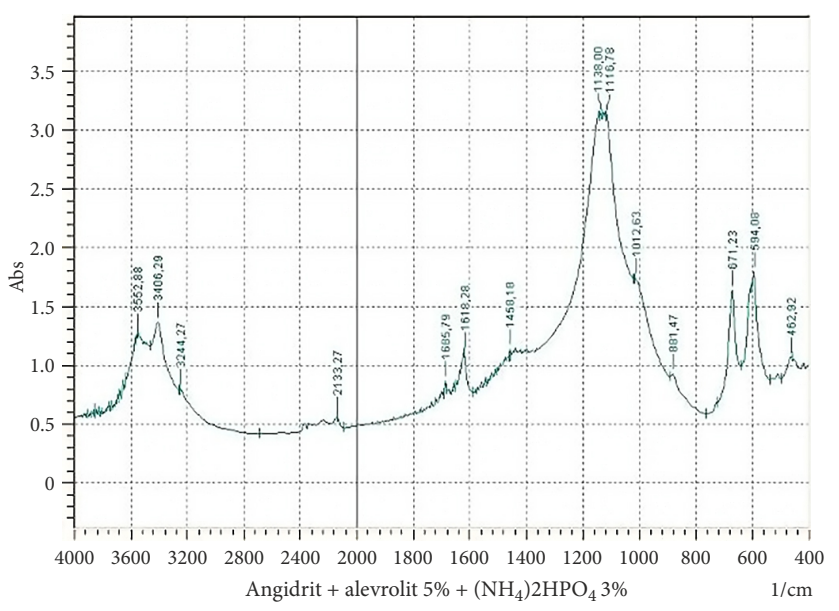

Figure 10. IR spectra of the samples: $\mathrm{a}$ - without siltstone; $\mathrm{b}$ - with the addition of natural siltstone 
Figure 12 and Figure 13, showed that the addition of siltstone and lime causes a significant increase in calcium $\mathrm{Ca}$ (1.3 and 1.6) and sulfur S (1.1 and 1.4) atoms content. On the other hand, the number of magnesium $\mathrm{Mg}$, oxygen $\mathrm{O}$, silicon $\mathrm{Si}$ and aluminum $\mathrm{Al}$ atoms decreases sharply, which is associated with dehydration of siltstone and destruction of the kaolinite crystal lattice during heating.
This process is accompanied by a significant loss in mass, which is confirmed by the results of differential thermal analysis of siltstone (Figure 2). The increase in the content of calcium $\mathrm{Ca}$ and sulfur $\mathrm{S}$ atoms is associated with an increase in both the content of crystalline hydrates of gypsum and other hydration products, formed due to the interaction of metakaolin and lime. a)

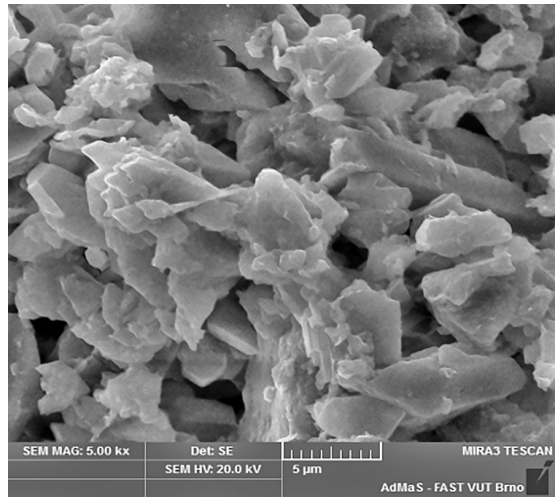

b)

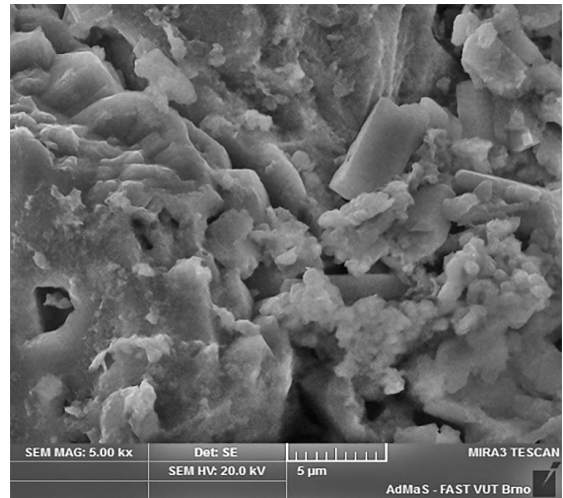

Figure 11. The microstructure of the anhydrite binder at 5000 magnification: a - with the addition of natural siltstone; $\mathrm{b}$ - with the addition of calcined siltstone and lime

a)

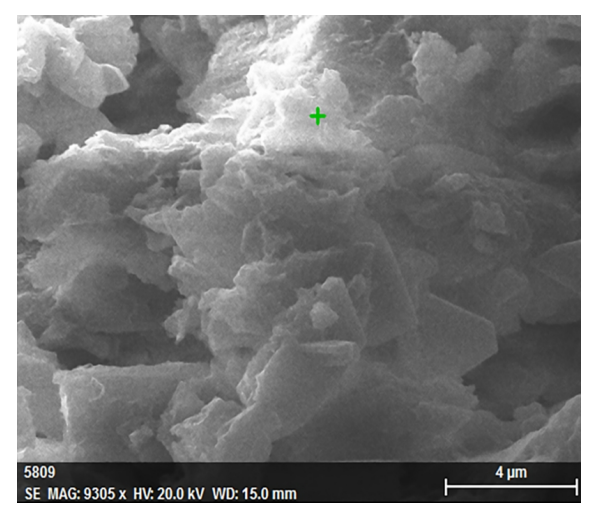

b)

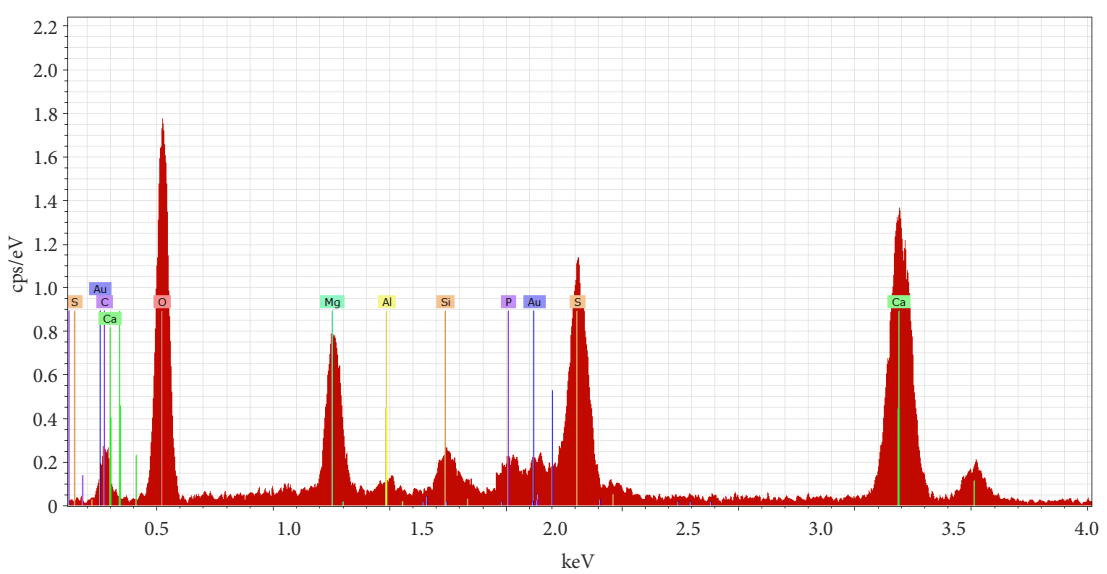

Figure 12. X-ray microanalysis of the anhydrite binder with the addition of natural siltstone: a - the microstructure of the gypsum stone; $\mathrm{b}$ - the chemical composition of the anhydrite binder microstructure fragment

a)

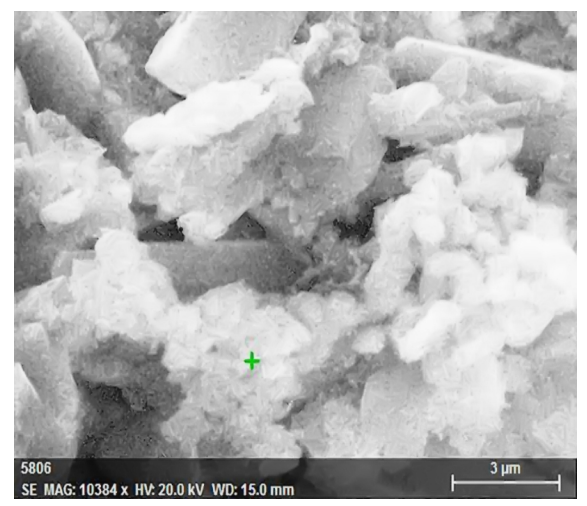

b)

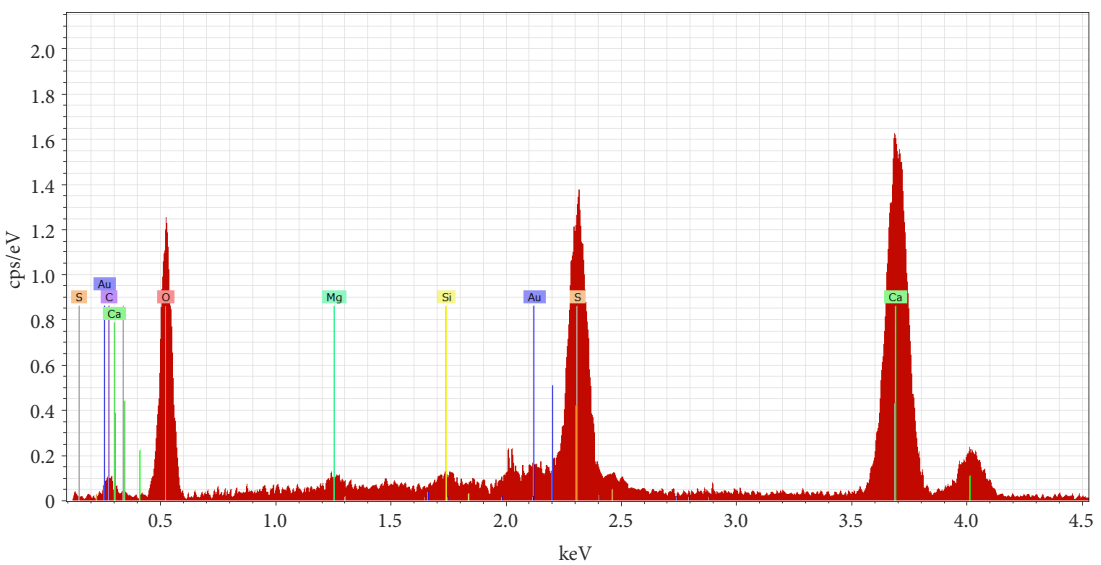

Figure 13. X-ray microanalysis of an anhydrite binder with the addition of calcined siltstone and lime: a - the microstructure of gypsum stone with of intergrowths of elongated crystals; $b$ - the chemical composition of the anhydrite binder microstructure fragment 


\section{Conclusions}

Based on the results of the research, the following conclusions can be drawn:

A study of the chemical and mineralogical composition and microstructure of siltstone showed the presence of aluminosilicate minerals in the siltstone with inclusions of mica, quartz, calcite and clay particles. The presence of these minerals in the composition of the anhydrite binder suggests that finely ground siltstone can be used as a mineral additive in order to accelerate the crystallization of gypsum neoplasms and densify the structure of gypsum stone.

For the first time, the effectiveness of using sodium and ammonium phosphates as hardening activators of an anhydrite binder was shown. Depending on the type of additive, strength characteristics were increased up to 2.5-4 times in comparison with the reference composition. Supposedly, the mechanism of additives action is based on their ability to create a highly alkaline environment, which helps to increase the degree of solubility of anhydrite and accelerates hydration process.

Siltstone, added to the composition in the amount from 0 to $5 \%$, lead to up to $40 \%$ increase in strength, which is due to the action of siltstone particles as "crystallization centers" and formation of crystalline hydrates of calcium sulfate dihydrate on their surface. At the same time, the additive is directly involved in the process of structural formation, which is confirmed by IR analysis.

The addition of siltstone, calcined in the temperature range $600-650{ }^{\circ} \mathrm{C}$, in an amount from 0 to $10 \%$ leads to a sharp decrease in the strength of anhydrite samples, reaching 4 times with an additive content of $10 \%$. However, when calcined siltstone is used together with lime, the strength characteristics increase to $45 \%$ due to additional compaction with the formation of new hydration products in the process of metakaolin and lime interaction.

Microstructural analysis showed that samples with calcined siltstone and lime have a more dense and uniform structure with a lower porosity, compared to the samples with natural siltstone. Moreover, the figures showed the formation of new highly dense hydration products in the form of intergrowths of elongated crystals and amorphous neoplasms, that additionally densify the structure of the anhydrite matrix.

$\mathrm{X}$-ray microanalysis of the anhydrite binder showed the most intense lines corresponding to calcium of $\mathrm{Ca}$, sulfur $\mathrm{S}$ and oxygen $\mathrm{O}$ atoms, which indicates a significant content of calcium sulfate crystalline hydrates in the composition of gypsum stone.

Thus, the analysis of the results obtained by various methods shows the effectiveness of using natural siltstone as an active mineral additive and the effectiveness of using calcined siltstone together with lime in the composition of the anhydrite binder.

\section{References}

Altykis, M. G., Khaliullin, M. I., Rakhimov, R. Z., Morozov, V. P., \& Bakhtin, A. I. (1996). On the mechanism of structural transformations of gypsum binders based on $\mathrm{CaSO}_{4}$ anhydrite in the hardening process. Izvestiya vuzov. Stroitel'stvo, 12, 57-61. (In Russian).

Conley, R. F., \& Bundy, W. M. (1958). Mechanism of gypsification. Geochimica at Cosmochimia Acta, 15(1-2), 57-72. https://doi.org/10.1016/0016-7037(58)90010-3

Chen, H., Soles, J. A., \& Malhotra, V. M. (1993). Investigations of supplementary cementing materials for reducing alkali-aggregate reactions. Cement and Concrete Composites, 15(1-2), 75-84. https://doi.org/10.1016/0958-9465(93)90039-C

Escalante-García, J. I., Martínez-Aguilar, O. A., \& Gomez-Zamorano, L. Y. (2017). Calcium sulphate anhydrite based composite binders; effect of Portland cement and four pozzolans on the hydration and strength. Cement and Concrete Composites, 82, 227-233.

https://doi.org/10.1016/j.cemconcomp.2017.05.012

Fomina, E. V., Lesovik, V. S., Fomin, A. E., Absimetov, M. V., \& Elistratkin, M. Yu. (2018). Increasing the effectiveness of aerated concrete by using coal waste. Regional'naya arkhitektura i stroitel'stvo, 4(37), 38-47. (In Russian).

Habert, G., Choupay, N., Escadeillas, G., Guillaume, D., \& Montel, J. M. (2009). Clay content of argillites: Influence on cement based mortars. Applied Clay Science, 43(3-4), 322-330. https://doi.org/10.1016/j.clay.2008.09.009

Juenger, M. C. G., Snellings, R., \& Bernal, S. A. (2019). Supplementary cementitious materials: New sources, characterization, and performance insights. Cement and Concrete Research, 122, 257-273.

https://doi.org/10.1016/j.cemconres.2019.05.008

Kondratieva, N., Barre, M., Goutenoire, F., \& Sanytsky, M. (2017). Study of modified gypsum binder. Construction and Building Materials, 149, 535-542.

https://doi.org/10.1016/j.conbuildmat.2017.05.140

Konovalov, V. M., Glikin, D. M., \& Solomatova, S. S. (2015). The use of argillite in the production of mixed cements. Sovremennyye problemy nauki i obrazovaniya, 2(2), p. 96. (In Russian).

Krejsová, J., Doleželová, M., Pernicová, R., Svora P., \& Vimmrová, A. (2018). The influence of different aggregates on the behavior and properties of gypsum mortars, Cement and Concrete Composites, 92, 188-197.

https://doi.org/10.1016/j.cemconcomp.2018.06.007

Magallanes-Rivera, R. X., Juarez-Alvarado, C. A., Valdez, P., \& Mendoza-Rangel, J. M. (2012). Modified gypsum compounds: An ecological-economical choice to improve traditional plasters. Construction and Building Materials, 37, 591-596. https://doi.org/10.1016/j.conbuildmat.2012.07.054

Magallanes-Rivera, R. X., \& Escalante-García, J. I. (2014). Anhydrite/hemihydrate-blast furnace slag cementitious composites: Strength development and reactivity. Construction and Building Materials, 65, 20-28.

https://doi.org/10.1016/j.conbuildmat.2014.04.056

Sakthieswaran, N., \& Sophia, M. (2019). Synergistic effect of mineral admixture and bio-carbonate fillers on the physicomechanical properties of gypsum plaster. Construction and Building Materials, 204, 419-439.

https://doi.org/10.1016/j.conbuildmat.2019.01.160 
Sakthieswaran, N., \& Sophia, M. (2018). Effect of superplasticizers on the properties of latex modified gypsum plaster. Construction and Building Materials, 179, 675-691.

https://doi.org/10.1016/j.conbuildmat.2018.05.150

Sergeeva, N. A., \& Sycheva, L. I. (2017). The effect of additives on the properties of anhydrite binder. Uspekhi $v$ khimii $i$ khimicheskoy tekhnologii, 32(2-198), 158-160. (In Russian).

Sergeeva, N. A., \& Sycheva, L. I. (2017). The influence of the structure of the anhydrite component on the properties of multiphase gypsum binders. Uspekhi $v$ khimii $i$ khimicheskoy tekhnologii, 31(3-184), 102-104. (In Russian).

Singh, M., \& Garg, M. (2000). Making of anhydrite cement from waste gypsum. Cement and Concrete Research, 30(4), 571577. https://doi.org/10.1016/S0008-8846(00)00209-X

Singh, M., \& Garg, M. (2004). Study on anhydrite plaster from waste phosphogypsum for use in polymerised flooring composition. Construction and Building Materials, 19(1), 25-29. https://doi.org/10.1016/j.conbuildmat.2004.04.038

Singh, N. B., \& Middendorf, B. (2007). Calcium sulphate hemihydrate hydration leading to gypsum crystallization. Progress in Crystal Growth and Characterization of Materials, 53, 5777. https://doi.org/10.1016/j.pcrysgrow.2007.01.002

Tzouvalas, G., Dermatas, N., \& Tsimas, S. (2004). Alternative calcium sulfate-bearing materials as cement retarders: Part I. Anhydrite. Cement and Concrete Research, 34(11), 21132118. https://doi.org/10.1016/j.cemconres.2004.03.020

Wang, W., Zeng, D., Chen, Q., \& Yin, X. (2013). Experimental determination and modeling of gypsum and insoluble anhydrite solubility in the system $\mathrm{CaSO}_{4}-\mathrm{H}_{2} \mathrm{SO}_{4}-\mathrm{H}_{2} \mathrm{O}$. Chemical Engineering Science, 101, 120-129.

https://doi.org/10.1016/j.ces.2013.06.023 